\title{
A assistência social e 0 ativismo judicial na perspectiva da dignidade humana
}

The social assistance and the judicial activim in the perpective of the human being dignity

Christiane Splicido ${ }^{1}$

\section{Resumo}

\begin{abstract}
A assistência social, inserida no ordenamento constitucional, artigo 203 da Constituição Federal de 1988, e regulamentada pela Lei Federal n.o 8.742/93, veio para atender àqueles que não possuem as mínimas condições de contribuir para a Previdência Social, possibilitando a diminuição das desigualdades, a fim de garantir a dignidade mínima da pessoa humana, permitindo-lhes real exercício da cidadania. Contudo, o critério etário para concessão do benefício assistencial gera polêmicas ante o Estatuto do Idoso, que considera pessoa idosa aquela que possui 60 anos ou mais, enquanto a Assistência Social concede o Benefício de Prestação Continuada aos idosos que contam com mais de 65 anos. Para resolver tal impasse, utiliza-se o princípio da dignidade da pessoa humana, fundamento da Constituição Federal de 1988, para, então, aplicar o ativismo judicial revelador, podendo chegar a um resultado em que todos os cidadãos são dignos e, portanto, fazem jus ao benefício assistencial.
\end{abstract}

Palavras-chave: Lei orgânica da assistência Social. Princípio da Dignidade da Pessoa Humana. Constituição Federal. Ativismo judicial. Critério etário.

\begin{abstract}
The social assistance, inserted in the constitutional order, article 203 of the Constitution Federal of 1988, and regulated for the Federal Law n.o 8.742/93, came to take care of to those that do not possess the minimum conditions to contribute for the social welfare, making possible the reduction of the inaqualities, in order to guarantee the minimum dignity of the person human being, allowing them real exercise of the citizenship. However, the aged criterion for concession of the assistencial benefit generates controversies before the Statute of the Aged one, that it considers elderly that one that possesss 60 years more or, while the Social Assistance grants the Benefit of Continued Installment the aged ones that they count more than on 65 years. To decide such impasse, human being uses itself the beginning of the dignity of the person, bedding of the Federal Constitution of 1988, for, then, to apply the revealing judicial activism, being able to arrive at a result where all the worthy citizens are $e$, therefore, they make jus to the assistencial benefit.
\end{abstract}

Keywords: Organic Law of the Social Assistance. Principle of dignity of the person human. Constitution Federal. Judicial activism. Aged criterion.

\footnotetext{
Advogada. Especializada em Direito Aplicado pela Escola da Magistratura do Paraná Pós-graduanda em Direito Previdenciário pela Universidade Anhanguera - UNIDERP. Mestranda em Teoria do Direito e do Estado pelo Centro Universitário Eurípides de Marília. chrisplicido@terra.com.br
} 


\section{Introdução}

A temática da Assistência Social está inserida no contexto constitucional da Seguridade Social e da ordem social, sendo o primeiro valor a dignidade da pessoa humana, o qual pode ser considerado como fonte de todos os demais. É da natureza social do homem que decorre a preocupação de todos com o respeito à dignidade. Em toda a vida social essa dignidade estará presente.

A Constituição Federal consagra no artigo 1ํㅡ. III, como princípio universal, como seu fundamento, a dignidade da pessoa humana, resultando na obrigação do Estado em garantir um patamar mínimo de recursos, capaz de prover-lhes a subsistência.

Contudo, o Direito realiza-se com a interpretação da lei, a qual, necessariamente, deve levar em consideração a realidade social, política, econômica e cultural da sociedade, e sempre pautada à luz dos princípios constitucionais e direitos fundamentais.

Ante o conceito de Direito, intimamente ligado está o conceito de Justiça. E, para tanto, necessário se faz abordar tal tema sob o enfoque de um dos maiores filósofos que teve uma imensa influência sobre a cultura ocidental, Aristóteles (384-322 a.C.).

No que tange ao conceito de justiça, Aristóteles (1973), em sua obra Ética a Nicômaco - livro $V$, a justiça é o principal fundamento da ordem do mundo, logo é inseparável da vida em sociedade. Com isso, nota-se que o conceitual aristoteliano (BITTAR, 1999), abrange princípios, virtudes, direitos.

A teoria aristotélica divide o conceito de justiça em dois: a comutativa e a reparativa. A primeira cuida da justiça preventiva, enquanto a segunda repara as injustiças.

A fim de se fazer Justiça, colocando o Direito em prática, depara-se com um dos variados instrumentos jurídicos inserido no artigo 203, incisos I a V, dispondo a Constituição Federal que a:

Assistência Social será prestada a quem dela necessitar, independentemente de contribuição à seguridade social, tendo por objetivos a proteção à família, à maternidade, à infância, à adolescência e à velhice, o amparo às crianças e aos adolescentes carentes, a promoção da integração ao mercado, a habilitação e reabilitação das pessoas portadoras de deficiência e a promoção de sua integração à vida comunitária e, finalmente, a garantia de um salário mínimo de benefício mensal à pessoa com deficiência e ao idoso que comprovem não possuir meios de prover a própria manutenção ou de tê-la provida por sua família, conforme dispuser a lei. 
Normatizando o assunto, adveio a Lei no. 8.742/93 que dispõe sobre a organização da Assistência Social, disciplinada em seu artigo 20 a garantia do benefício de prestação continuada no valor de um salário mínimo mensal à pessoa portadora de deficiência e ao idoso (atualmente com 65 anos), que comprovem não possuir meios de prover a própria manutenção e nem tê-la provida por sua família.

Para traçar limites ao poder de julgar, fala-se ativismo judicial, principalmente quando a assistência social não é observada, dentro de preceitos constitucionais que reforçam como fundamental o direito à vida e à saúde, que não existem sem o substrato assistencial mínimo e, para esta análise, toda atenção é voltada aos requisitos impostos pela Lei Orgânica da Assistência Social em face dos direitos humanos, pois por conta de seu não cumprimento é que o magistrado se vê, muitas vezes, em sua função atípica para analisar um conjunto de requisitos, e não apenas um específico.

Essa mudança de paradigma para desenvolver um comportamento ativo e criativo pelo juiz ante as novas e complexas questões que surgem com os casos concretos, os quais abrangem uma dimensão coletiva do direito, que muito embora deixem os demais Poderes em situação desconfortável, têm grande probabilidade de mutação dessa relação, cujo resultado terá o enriquecimento da função jurisdicional.

Os limites do magistrado ao julgar uma lide em que a assistência social é desrespeitada, irão até a aplicação dos princípios constitucionais na condição de norma cogente no contexto do ativismo judicial e de acordo com a vontade do Poder Constituinte.

O intuito é possibilitar a manutenção do direito fundamental à vida e à saúde em um substrato natural, em que a espécie humana e os demais seres possam viver de forma digna. A aplicação do direito pelo magistrado como protetor dos direitos e garantias constitucionais fundamentais dá prioridade aos princípios da efetividade e da dignidade humana. O papel ativo do magistrado nas questões previdenciárias, principalmente no que tange à assistência social, indica que este deve romper de forma criativa e fundamentada todos os elos das correntes normativas que o escravizam a forma, com objetivo claro de defesa dos direitos daqueles que mais necessitam.

Assim, o acesso à justiça é estudado desde Aristóteles, em séculos antes de Cristo, pois era em Roma, por exemplo, que surgiu o conceito de justiça gratuita que, por força da 
doutrina cristã, tinha como lema o amor ao próximo, isentava os menos favorecidos das custas processuais, garantindo, assim, o acesso à justiça.

A Carta Cidadã de 1988, em seu artigo 3ํ, inciso IV, estabelece, além de uma sociedade justa, a erradicação da pobreza e da redução das desigualdades sociais, que é um dos objetivos fundamentais do Estado, qual seja, o de promover o bem estar de todos, sem preconceito ou discriminação.

Desta forma, a promoção do bem-estar social pode ser resumida pelo artigo 3으, incisos I a IV, da Carta Magna, regulamentando os objetivos da República Federativa do Brasil, quais sejam, a construção de uma sociedade livre, justa e solidária; a garantia do desenvolvimento nacional; a erradicação da pobreza, bem como da marginalização; redução das desigualdades sociais e regionais e sociais e, finalmente, a promoção do bem de todos, sem preconceitos de origem, raça, sexo, cor, idade e quaisquer outras formas de discriminação.

Assim, para se fazer justiça deve-se colocar plenamente em prática os dispositivos constitucionais, para somente assim, satisfazer os anseios dos cidadãos brasileiros e respeitar seus direitos fundamentais - direito a uma vida digna e, para isso, deve ser considerada a consagração constitucional da dignidade da pessoa humana resultante da obrigação do Estado em prover a quem dela necessitar os mínimos sociais, a fim de que seja possível sua emancipação e plena inclusão social.

Nesse contexto, o enfrentamento do assunto em epígrafe a poderá contribuir, em nível acadêmico e científico, para uma compreensão adequada dos pontos favoráveis ou problemáticos da pesquisa aqui proposta.

A par destas considerações, o trabalho tem relevância social que pode ser verificada por meio de dados empíricos que demonstram o papel de relevo assumido pela Assistência Social no Brasil, decorrência das conquistas obtidas pela em nível de Seguridade Social, bemestar e justiças sociais, suas áreas de abrangência, assim como seus princípios norteadores. Ainda, ao longo histórico da Assistência Social, seus conceitos, verifica-se que a Lei Orgânica da Assistência Social é de suma importância para os dias atuais, em que a informação é primordial aos destinatários do Benefício de Prestação Continuada, professando, com isso, uma inclusão social mais abrangente e humana, atendendo, de forma mais abrangente, o anseio daqueles que se vêem mais necessitados e, finalmente, quando se trata acerca do 
Benefício de Prestação Continuada como instrumento de alcance à dignidade da pessoa humana.

Por fim, com o presente estudo, pretende-se compreender os anseios da Lei Orgânica da Assistência Social, bem como suas limitações e possibilidades de alterações ou reformas, a busca por uma efetiva universalidade de cobertura e, ainda, a extensão do sistema protetivo aqui em debate a um número cada vez maior de necessitados, os quais, hoje, encontram-se muitas vezes desamparados, promovendo, com isso, a efetivação das garantias sensivelmente esculpidas na Carta Magna.

\section{Uma tentativa de conceituação dos princípios}

Ao se tratar de princípios, necessário se faz denominar a terminologia enfocada, em razão da polissemia da expressão "princípio" que é derivado do latim principium (origem, começo) em sentido vulgar quer exprimir o começo da vida ou o primeiro instante em que as pessoas ou as coisas começaram a existir. É, amplamente, indicativo do começo ou origem de qualquer coisa.

No sentido jurídico, notadamente no plural, quer significar as normas elementares ou os requisitos primordiais instituídos como base, como alicerce de alguma coisa. E, assim, princípios revelam o conjunto de regras ou preceitos, que se fixaram para servir de norma a toda ação jurídica, traçando, desta forma, a conduta a ser tida em qualquer operação jurídica.

Desse modo, exprimem sentido, mostrando a própria razão fundamental de ser das coisas jurídicas, convertendo-se em axiomas, e, por outro lado, possivelmente o mais importante, é em virtude da condição elevada que assumem os princípios jurídicos para o conhecimento e aplicação do direito (SILVA, 1989, p. 433).

Os princípios jurídicos são os pontos básicos, os quais servem de apoio para o início da aplicação dos dispositivos jurídicos, pois são a base do Direito. E, neste raciocínio, incluem-se os fundamentos da Ciência Jurídica, em que se firmaram as normas originárias ou as leis científicas do Direito, as quais traçam as noções em que se estrutura a própria ciência. Assim, são considerados como preceitos fundamentais para a prática do Direito e proteção aos direitos. 
Para Miguel Reale (2002, p. 60), os "princípios são, pois, verdades ou juízos fundamentais", os quais constituem alicerce a fim de garantir a concretude de um conjunto de preceitos, o que nada mais é do que um sistema de conceitos relativos a dada porção da realidade. Há, ainda, princípios que não são explícitos, que não resultam de evidências, mas nem por isso deixam de ter validade dentro do ordenamento.

Nesta mesma linha de pensamento, com o intuito de ratificar, pode-se citar a lição de Celso Antônio Bandeira de Mello (1999, p. 230) de que:

\begin{abstract}
Princípio é, por definição, mandamento nuclear de um sistema, verdadeiro alicerce dele, disposição fundamental que se irradia sobre diferentes normas compondoIhes o espírito e servindo de critério para a sua exata compreensão e inteligência, exatamente por definir a lógica e a racionalidade do sistema normativo, no que the confere a tônica e lhe dá sentido harmônico. É o conhecimento do princípio que preside a intelecção das diferentes partes componentes do todo unitário que há por nome sistema jurídico positivo. Violar um princípio é muito mais grave que transgredir uma norma. A desatenção ao princípio implica ofensa não apenas a um específico mandamento obrigatório, mas a todo sistema de comandos. É a mais grave forma de ilegalidade ou inconstitucionalidade, conforme o escalão do princípio atingido, porque representa insurgência contra todo o sistema, subversão de seus valores fundamentais, contumédia irremissível a seu arcabouço lógico e corrosão de sua estrutura mestra.
\end{abstract}

Atualmente, não que se falar em aplicação auxiliar dos princípios, sendo eles dotados de juridicidade. Muito embora os princípios possuam certa vagueza e generalidade, o que permite que sejam aplicados a vários casos distintos ou correlatos, eles possuem significados determinados, o que não significa que sejam imprecisos.

Por serem os princípios de natureza aberta, ampla, acompanham a evolução social, adequando-se às inúmeras situações práticas. O princípio da dignidade da pessoa humana é considerado um princípio com status de garantia constitucional. Poder-se-ia, então, dizer que tal princípio é um princípio fundamental? Tal resposta comporta certa subjetividade, pois depende do que o operador do sistema de princípios e fundamentos entende por dignidade da pessoa humana, servindo como fonte de resolução jurídica.

Para alguns autores brasileiros, princípios jurídicos fundamentais carregam uma carga axiológica, bem como política, a fim de estruturar o Estado e suas decisões. Com isso, os princípios jurídicos fundamentais, enquanto valor, foram positivados na Constituição Federal de 1988. 
Desta forma, devido à importância que os princípios apresentam para o ordenamento jurídico, necessário se faz distingui-los das regras, para então adentrar no campo fértil da dignidade da pessoa humana.

\section{Distinção entre princípios e regras}

Relevante mencionar que os princípios distinguem-se das demais regras em diversos aspectos, podendo ser pelo conteúdo, em que os princípios incorporam primeira e diretamente os valores ditos fundamentais, enquanto as regras destes se ocupam mediatamente, num segundo momento, como também pela apresentação ou forma enunciativa, que é vaga, ampla, aberta dos princípios, contra uma maior especificidade das regras.

Os princípios incidem sempre, porém, normalmente mediado por regras, sem excluir outros princípios concorrentes e sem desconsiderar outros princípios divergentes, que podem conjugar-se ou ser afastados apenas para o caso concreto.

Assim, se por sua vez as regras incidem direta e exclusivamente, constituindo aplicação integral, porém não exaustiva, conclui-se que princípios e regras traduzem expressões distintas ou variedades de um mesmo gênero: normas jurídicas.

Segundo a lição de Juarez Freitas (2002, p. 56), os princípios distinguem-se das regras, como argumenta em sua obra:

\footnotetext{
Não propriamente por generalidades, mas por qualidade argumentativa superior, de modo que, havendo colisão, deve ser realizada uma interpretação em conformidade com os princípios (dada à fundamentalidade dos mesmos), sem que as regras, por supostamente apresentarem fundamentos definitivos, devam preponderar.
}

Ainda, segundo a referida distinção pode-se dizer que as regras obrigam, proíbem ou permitem alguma coisa, enquanto que os princípios "são normas que exigem a realização de algo, da melhor forma possível, de acordo com as possibilidades fáticas e jurídicas" (CANOTILHO, 1988, p. 1123).

Assim, por princípios se depreende espécies de norma, que são, lógica e qualitativamente, diferentes das regras, ainda que ambos possuam igual positividade. São, numa palavra, princípios expressos constitucionalmente, princípios positivos. 
Ensina Herbert Hart (1986, p. 91) que, na busca sobre a natureza do Direito, há certas questões principais recorrentes e uma delas refere-se a que o sistema jurídico consiste, em geral, em regras. Ele mesmo constrói um modelo complexo, o Direito como a união entre regras primárias e regras secundárias, que é, assim, "a chave para a ciência do direito".

Regra esta que, enquanto padrão de comportamento, "um guia de conduta da vida social" não é, de forma alguma, uma ideia simples. Há, por conseguinte, necessidade de assinalar os diferentes tipos. Assim, distinguem-se as regras primárias e as regras secundárias. Aquelas determinam que as pessoas façam ou se abstenham de fazer certas ações; estas asseguram às pessoas a possibilidade de criar, extinguir, modificar, julgar as regras primárias. Segundo as palavras de Hart (1986) "as regras do primeiro tipo impõem deveres, as regras do segundo tipo atribuem poderes, público ou privado".

Por sua vez, as regras secundárias são de três tipos, a saber:

a) de reconhecimento (rule of recognition), permitem definir quais as regras que pertencem ao ordenamento, tendo por escopo eliminar as incertezas quanto às regras primárias; b) de alteração (rules of change), que conferem poder a um indivíduo ou a um corpo de indivíduos para introduzir novas regras primárias e eliminar as antigas, impedindo, assim, que sejam estáticas; c) de julgamento ou de adjudicação (rule of adjudication), dão poder aos indivíduos para proferir determinações dotadas de autoridade respeitantes à questão sobre se, num caso concreto, foi violada uma regra primária.

Por sua vez, o jusfilósofo norteamericano Ronald Dworkin, sucessor de Herbert Hart na Cattedra de Jurisprudence na Universidade de Oxford, objetiva apresentar as insuficiências seja do positivismo seja do utilitarismo. Para tanto, valer-se-á, sobretudo, da diferença, de caráter lógico, entre princípio e regra. O direito é, pois, para ele um sistema de regras e princípios.

Por meio dos chamados casos-limites ou hard cases, Dworkin monstra que quando os juristas debatem e decidem em termos de direitos e obrigações jurídicas, eles utilizam standards que não funcionam como regras, mas trabalham com princípios, política e outros gêneros de standards.

Desta forma, para Dworkin os princípios são exigências de justiça, de equidade ou de qualquer outra dimensão da moral. Consequentemente, "a validade de um direito dependa não de uma determinada regra positiva, mas de complexos problemas morais", 
inexistindo a dicotomia entre questões de direito e questões de justiça, em que se supera a antinomia clássica Direito Natural/Direito Positivo.

Afirmar que os juristas empregam princípios e não regras é admitir que são duas espécies de norma, cuja diferença é de caráter lógico. Embora orientem para decisões específicas sobre questões de obrigações jurídicas, diferem pela feição da orientação que sugerem. Assim, as regras indicam consequências jurídicas que se seguem automaticamente quando ocorrem as condições previstas.

Um princípio não estabelece as condições que tornam sua aplicação necessária. Ao contrário, determina uma razão que impulsiona o intérprete numa direção, mas que não demanda uma decisão específica, única. Assim, pode acontecer que um princípio, numa certa circunstância, e frente a outro princípio, não prevaleça, o que não significa que ele perca a sua condição de princípio, muito menos que deixe de pertencer ao sistema jurídico.

Já as regras, ao contrário dos princípios, são aplicáveis em todo seu conteúdo literal. Aos elementos por elas estabelecidos, verificar-se-á se a regra é válida, aceitando a consequência aplicável ou, então, a regra é inválida e, em tal caso, não influi sobre a decisão.

Conclui-se, assim, que os princípios possuem uma proporção de importância que as regras não têm, pois quando os princípios entram em conflito, para resolvê-lo é necessário ter em consideração a proporção relativa de cada um. Necessário valorar todos os princípios concorrentes e controversos que ele traz consigo, a fim de encontrar uma conciliação entre eles.

As regras não possuem esta proporção. Contudo, não se pode atribuir maior valor a uma regra do que a outra dentro do sistema jurídico, no sentido de que, se duas regras colidem, uma prevalece sobre a outra em virtude de sua maior dimensão.

Cabe salientar, portanto, que se duas regras colidem, então uma delas não pode ser válida, consequentemente, cada sistema jurídico possuirá meios que possibilitem regular e decidir tais conflitos. A este conflito a doutrina denomina antinomia, que são resolvidas pelos critérios: cronológico, hierárquico, da especialidade.

O pensamento de Ronald Dworkin é retomado, dentro do sistema da civil law, pelo constitucionalista alemão Robert Alexy (1993, p. 99), que, considerando o modelo do jusfilósofo americano demasiado simple busca formular un modelo más diferenciado. 
A teoria dos princípios de Robert Alexy, bem como a distinção entre princípios e regras, constitui o marco de uma teoria normativa-material dos direitos fundamentais e, com ela, o ponto de partida para responder à pergunta acerca da possibilidade e dos limites da racionalidade no âmbito destes direitos, tornando-se a base da fundamentação jusfundamental e a chave para a solução dos problemas centrais da dogmática dos direitos fundamentais.

Assim, sem uma perfeita compreensão desta distinção, própria da estrutura das normas de direito fundamental, é impossível formular-se uma teoria adequada dos limites dos direitos fundamentais, quanto à colisão entre estes e uma teoria suficiente acerca do papel que eles desempenham no sistema jurídico.

Para Robert Alexy, princípios são mandados de otimização, isto é, são normas que ordenam algo que deve ser realizado na maior medida possível, dentro das possibilidades jurídicas e reais existentes, e que podem ser cumpridos em diferentes graus e que a medida devida de seu cumprimento depende não somente das possibilidades reais, mas também das jurídicas. Este é o ponto decisivo para distinção das regras.

Por sua vez, as regras, guias de conduta, são normas que somente podem ser cumpridas ou não, as quais contém determinações fáticas e juridicamente possível. Isto significa que a diferença entre regras e princípios é qualitativa, e não apenas de grau.

Entretanto, a distinção entre regras e princípios se mostra mais claramente nas colisões de princípios e nos conflitos de regras. Embora apresentem um aspecto em comum, diferenciam-se, fundamentalmente, na forma como se soluciona o conflito.

Assim, os conflitos de regras se resolvem na dimensão de validez, ou seja, somente podem ser solucionados introduzindo-se uma regra de exceção, debilitando o seu caráter definitivo, ou declarando-se inválida uma das regras. Com efeito, uma norma vale ou não juridicamente e, se ela vale e é aplicável a um caso, significa que vale também sua consequência jurídica.

Então, o conflito entre duas regras há de ser solucionado por outras regras, pelos critérios cronológico e hierárquico, concluindo Alexy que lo fundamental es que la decisión es una decisión acerca de la validez.

De sua banda, a colisão de princípios se resolve pela proporção, tal como o expressa Ronald Dworkin. Quando dois princípios entram em colisão, um dos dois tem que ceder 
frente ao outro, porquanto um limita a possibilidade jurídica do outro. O que não implica que o princípio desprezado seja inválido, pois a colisão de princípios se dá apenas entre princípios válidos.

\section{Breve estudo sobre o principio da dignidade da pessoa humana}

Por tanto se tratar do princípio da dignidade da pessoa humana útil referendar acerca do que vem a ser dignidade, antes de adentrar ao princípio da dignidade da pessoa humana como fundamento da Constituição Federal de 1988.

\section{Conceito de dignidade}

O conceito em questão partiu do latim dignitas e foi construído ao longo dos anos, chegando ao século XXI com valor supremo, estruturado a partir da razão jurídica.

A dignidade é garantida por um princípio, sendo, portanto, plena. Como já acerca dos princípios, a dignidade também deve passar ilesa pelas conturbações que atingem a sociedade, sendo invariável.

Com isso, imprescindível apontar a dignidade da pessoa humana como intangível, sendo obrigação de todo o poder público respeitá-la e protegê-la. Nota-se, portanto, que a dignidade nasce com a pessoa "que exactamente nesta pureza da sua origem reside a sua dignidade para nos servirem de princípios práticos supremos" (KANT, 1997, p. 46), sendo inerente a sua essência e definida a partir das experiências históricas. "O ser humano é digno porque é".

E como desde os primórdios, o homem não vive sozinho, mas sim no meio social, a preocupação com sua dignidade aumenta, pois:

\footnotetext{
chega um momento de seu desenvolvimento que seu pensamento tem de ser respeitado, suas ações e seu comportamento - isto é, sua liberdade -, sua imagem, sua intimidade, sua consciência - religiosa, científica, espiritual - etc., tudo compõe sua dignidade.
}

Toda pessoa humana traz consigo a dignidade, independente de sua situação social, pelo simples fato de existir, como já se referia Kant (1997) que "[...] o homem, e, duma maneira geral, todo o ser racional, existe como um fim em si mesmo". E é justamente pelo 
fato do homem existir e coexistir em sociedade que a dignidade pode aumentar ou diminuir, devendo-se acrescer um limite social à garantia desta, isto é, haverá dignidade ilimitada desde que não se viole outra ou a de outrem. Aqui vale lembrar que nem a própria dignidade é permitida a violação, cabendo ao Estado o dever de preservar quaisquer situações que coloquem em risco a dignidade humana.

Continuando com o pensamento kantiniano:

Os seres cuja existência depende, não em verdade da nossa vontade, mas da natureza, têm contudo, se são seres irracionais, apenas um valor relativo como meios e por isso se chama coisas, ao passo que os seres racionais se chamam pessoas, porque a sua natureza os distingue já como fins em si mesmos, quer dizer como algo que não pode ser empregado como simples meio e que, por conseguinte, limita nessa medida todo arbítrio. (KANT, 1997, p. 68).

Esse raciocínio explica a autonomia da dignidade, sendo esta reproduzida pela capacidade racional do ser humano, de pensamento. Com isso, Kant aponta que a autonomia da vontade é um atributo apenas encontrado nos seres racionais, pois:

No reino dos fins tudo tem ou um preço ou uma dignidade. Quando um coisa tem um preço, pode-se pôr em vez dela qualquer outra como equivalente; mas quando uma coisa está acima de todo o preço, e portanto não permite equivalente, então ela tem dignidade. (KANT, 1997, p.77).

O entendimento de Kant parece ser o ser o mais adequado quando concilia a dimensão axiológica com a noção de autonomia, racionalidade e moralidade concebidas como fundamento e conteúdo da dignidade, pois justifica os direitos humanos fundamentais.

Desta forma, o pensamento kantiniano e as demais teorias que sustentam ser a dignidade atributo exclusivo da pessoa humana, privilegiando esta acima de outras espécies em função do racionalismo, sofre muitas críticas por conta do antropocentrismo. A começar por Hegel que considera um ser humano com dignidade a partir do momento em que este se torna um cidadão, o que não significa que seja desde o seu nascimento, conforme afirma Kant.

Com Hegel vislumbra-se o reconhecimento da capacidade jurídica, isto é, a competência do ser humano em ser sujeito de direitos, estendendo-se a todas as pessoas. 0 pensamento de Hegel demonstra a atribuição de direitos no sentido da noção de 
personalidade jurídica e não mero objeto de direitos a própria nota distintiva da dignidade da pessoa humana.

Com isso, Hegel se distancia do pensamento de Kant, o qual é o predominante deste estudo, bem como da maioria dos autores estudiosos sobre o tema. E, mesmo assim, a dignidade da pessoa humana, mantém-se ocupando lugar central no pensamento filosófico, político e jurídico, o que explica a sua qualificação como valor fundamental da ordem jurídica.

Encontra-se, ainda, o termo dignidade na Declaração Universal dos Direitos Humanos, a qual foi aprovada em 10 de dezembro de 1948 pela ONU, fundamentando-se nos princípios dos direitos fundamentais da pessoa humana.

Na Declaração Universal dos Direitos Humanos há o "reconhecimento da dignidade inerente a todos os membros da família humana" (POZZOLI, 2001, p. 123), bem como a reafirmação da fé dos povos das Nações Unidas na dignidade e no valor da pessoa humana.

No século XVIII, em que se presenciava o jusnaturalismo, tem-se como pressuposto de que o homem, em virtude tão somente de sua condição humana e independentemente de qualquer outra circunstância, é titular de direitos que devem ser reconhecidos e respeitados por seus semelhantes e pelo Estado. A ideia de que o homem, por sua mera natureza humana, é titular de direitos, que justamente possibilitou o reconhecimento dos direitos humanos e a proteção também dos fracos e excluídos, e não apenas dos que foram contemplados com direitos pela lei, por contratos, em virtude de sua posição social e econômica.

E, por meio do pensamento cristão e humanista, o entendimento humanista de Jacques Maritain precedeu a Declaração Universal dos Direitos Humanos, o qual afirma que "a filosofia dos direitos humanos repousa sobre a ideia da lei natural" (POZZOLI, 2001, p. 129), apresentando deveres e direitos fundamentais e princípios de boa conduta.

Para Maritain a base dos direitos humanos está em sua natureza, expressão da lei natural, fundados na dignidade da pessoa humana, colocando em evidência o ser humano enquanto pessoa.

Nessa mesma linha de raciocínio, Sarlet (2002) ressalta que "a ideia do valor intrínseco da pessoa humana deita raízes já no pensamento clássico e no ideário cristão". 
Logo, a religião cristã traz, exclusivamente, no que tange ao conceito de dignidade da pessoa humana, referências de que o ser humano foi criado à imagem e semelhança de Deus.

Por fim, partindo do pensamento do cristianismo conclui-se que todo ser humano, e não apenas os cristãos, possuem um valor que lhe é próprio. Nota-se, portanto, que não há na Bíblia um conceito puro acerca do que vem a ser dignidade, mas sim uma concepção do ser humano, a qual perdura nos dias atuais.

\section{Princípio da dignidade da pessoa humana}

A Constituição Federal vigente é garantista, ou seja, ela é um instrumento que visa garantir o mínimo necessário para que os cidadãos tenham uma vida digna. Nela tem-se consagrado a dignidade da pessoa humana em forma de princípio constitucional, que é um elevado postulado constitucional, por meio do qual há a efetividade, ou deveria haver, do princípio da dignidade da pessoa humana.

Para Ingo Wolfgang Sarlet (2002, p. 32) entende-se por dignidade da pessoa humana:

\footnotetext{
A qualidade intrínseca e distintiva de cada ser humano que o faz merecedor do mesmo respeito e consideração por parte do Estado e da comunidade, implicando, neste sentido, um complexo de direitos e deveres fundamentais que assegurem a pessoa tanto contra todo e qualquer ato de cunho degradante e desumano, como venham a lhe garantir as condições existenciais mínimos para uma vida saudável, além de propiciar e promover sua participação ativa e co-responsável nos destinos da própria existência e da vida em comunhão com os demais seres humanos.
}

Com este raciocínio, pode concluir-se que a Constituição Federal de 1988 concede à dignidade da pessoa humana o caráter de principal direito fundamental constitucionalmente garantido, agindo como princípio maior para a interpretação de todos os direitos e garantias conferidos às pessoas pelo ordenamento jurídico.

Quando da abordagem do conceito de dignidade, necessário foi tratar da evolução histórica do termo e seus estudiosos, obrigatoriamente adentrando ao campo religioso. Mas aqui, juridicamente observando, não há como vincular o princípio à religião, sob pena de ser um "obstáculo à própria universalização e - neste sentido - um fator impeditivo de uma globalização da dignidade num contexto multicultural". 
Assim, para assegurar a validade intercultural do princípio da dignidade da pessoa humana, de tal sorte a alcançar vinculatividade mundial, o próprio conteúdo e significado do princípio deve ser necessariamente compreendido como interculturalmente válido e secularizado, portanto, mediante renúncia a qualquer concepção religiosa.

A aplicação concreta do princípio da dignidade da pessoa humana é um dever social, em que o operador do Direito se vê obrigado a gerir sua atuação social pautado em tal princípio estampado na Carta Magna.

Nos dizeres de Rizzatto Nunes (2002):

É um verdadeiro supraprincípio constitucional que ilumina todos os demais princípios e normas constitucionais e infraconstitucionais. E por isso não pode o Princípio da Dignidade da Pessoa Humana ser desconsiderado em nenhum ato de interpretação, aplicação ou criação de normas jurídicas.

Nota-se que o referido princípio é válido em qualquer contexto, a se pautar, por exemplo, no respeito dos direitos sociais que a Constituição Federal de 1988 traz no artigo 60 vinculado ao caput do art. 225 , atribuindo direitos mínimos a uma vida digna ao cidadão e, que somado aos direitos fundamentais, pode-se dizer que a Constituição Federal está a caminho da aplicabilidade do princípio da dignidade da pessoa humana.

No tópico acerca dos princípios tratou-se sobre estes como fundamentais e, após a explanação sobre dignidade e o princípio da dignidade da pessoa humana, tem-se que este "enquanto expressão positiva do valor fonte do ordenamento constitucional brasileiro [...] o valor que ele traduz será chamado a conformar, orientar e limitar a opção realizada" (MARTINS, 2003, p. 108).

Contudo, nesta esfera poderia se considerar o princípio da dignidade da pessoa humana como absoluto, ainda que correndo o risco de relativizar os outros diversos princípios que são tão importantes quanto este. Entretanto, há que se explicar que tal princípio é absoluto em seu conteúdo axiológico, portanto, seu valor é absoluto. Diferente de seu conteúdo normativo que deve observar os limites de sua incidência. Ademais, sempre será difícil estabelecer o conteúdo do princípio da dignidade da pessoa humana, pois muito embora haja um caso em concreto a ser aplicado, há o lado da normatividade e o entendimento axiológico, momento em que se analisa o papel do intérprete na construção do conceito e na aplicação de sua extensão. 
Em análise do termo dignidade no tópico acima, nota-se que é valor intrínseco ligado à pessoa humana, o qual nasce com o homem e o acompanha até a sua morte. Neste porte, pode-se falar em natureza absoluta do princípio da dignidade da pessoa humana, pois a Constituição Federal a colocou em seu mais elevado patamar axiológico, como condição humana, que identifica o homem como ser único e especial.

Assim, apesar das críticas feitas ao princípio em questão no sentido de ser absoluto, partindo-se do pressuposto que a dignidade é inerente ao homem, que nasce e morre com ele, tem conteúdo axiológico, logo se conclui ser um princípio fundamental absoluto.

\section{Lei orgânica da assistência social}

A pessoa considerada idosa e portadora de deficiência física, no ordenamento constitucional, na Carta Magna tem proteção fixada logo de início, pois assim prescreve o artigo 1으, incisos II e III, veja-se:

Art. 1--A República Federativa do Brasil, formada pela união indissolúvel dos Estados e Municípios e do Distrito Federal, constitui-se em Estado Democrático de Direito e tem como fundamentos:

[...]

III - a dignidade da pessoa humana;

Logo, o deficiente físico e/ou idoso possui status de cidadão e, por consequência, deve ser contemplado por todos os instrumentos asseguradores da dignidade humana aos brasileiros, sem distinção.

Ademais, a Constituição Federal de 1988, em seu artigo 3으, inciso IV, estabelece, além de uma sociedade justa, a erradicação da pobreza e da redução das desigualdades sociais, que é um dos objetivos fundamentais do Estado, qual seja, o de promover o bem estar de todos, sem preconceito ou discriminação.

Além disso, observa-se que no artigo 203, inciso V, quis beneficiar as pessoas que não têm acesso a qualquer fonte de renda, seja pela idade avançada, problemas de saúde, deficiência física e/ou mental, ou por limitações pessoais:

Art. 203 - A assistência social será prestada a quem dela necessitar, independentemente de contribuição à seguridade social, e tem por objetivos: 
V - a garantia de um salário mínimo de benefício mensal à pessoa portadora de deficiência e ao idoso que comprovem não possuir meios de prover à própria manutenção ou de tê-la provida por sua família, conforme dispuser a lei.

Nesse sentido, a lei 8.742 de 07/12/93, chamada Lei Orgânica da Assistência Social (LOAS) veio dispor sobre a organização da Assistência Social, amparando as pessoas que não são contribuintes para a Previdência Social.

Assim, dispõe o artigo 20 da Lei Orgânica da Assistência Social (Lei 8.742, de 07 de dezembro de 1993):

Art.20 - O benefício de prestação continuada é a garantia de 1 (um) salário mínimo mensal à pessoa portadora de deficiência e ao idoso com 70 (setenta) anos ou mais e que comprovem não possuir meios de prover a própria manutenção e nem de têla provida por sua família.

E, a partir de janeiro de 1998, conforme a Lei Federal no 9.720, a idade mínima para receber o benefício de prestação continuada foi reduzida de 70 (setenta) para 67 (sessenta e sete) anos. Contudo, esta idade seria reduzida para 65 (sessenta e cinco) anos, por força do artigo 38 da Lei. 8.742/93, a contar de janeiro de 2000, no entanto, a Lei 9.720/98 modificou a redação do art. 38 mantendo a idade de 67 (sessenta e sete) anos.

Já, por meio do Estatuto do Idoso, o legislador procurou ampliar a proteção social, provendo atendimento dos menos favorecidos, independentemente de contribuições e com benefícios em dinheiro (art. 34).

E, no artigo 1ำ, referido dispositivo estabelece que idosa é a pessoa que tem idade igual ou superior a 60 (sessenta) anos, a seguir: "Art. 1o - É instituído o estatuto do idoso, destinado a regular os direitos assegurados às pessoas com idade igual ou superior a 60 (sessenta) anos."

O grande drama é que para receber o benefício de prestação continuada, a renda per capita da família não pode ser superior a 1/4 (um quarto) do salário mínimo, e idade a partir de 65 anos (artigo 34 do Estatuto do Idoso).

No entanto, o critério é injusto em face da lamentável situação em que se encontra o idoso no Brasil.

Há de ressaltar que a natureza e a essência do benefício e/ou assistência social é a de beneficiar a quem dela necessitar, independentemente de contribuição à seguridade social, 
garantindo o valor de 01 (um) salário mínimo de benefício mensal à pessoa portadora de deficiência e ao idoso que comprove não possuir meios de prover à própria manutenção ou de tê-la provida por sua família, conforme dispõe a Lei Maior (art. 203).

Deste modo, o amparo social ao deficiente físico e ao idoso foi feito para amparar a pessoa, não contribuinte do Instituto Nacional do Seguro Social, incapaz profissionalmente seja por portar problemas físicos e/ou mentais ou de avançada idade.

Assim, constatadas a incapacidade física/idade e a carência de condição de sobrevivência digna, impõe-se a concessão do benefício de natureza assistencial. É nesse sentido que os tribunais federais têm se posicionado, conforme infracitado:

TRIBUNAL REGIONAL FEDERAL - 3 REGIÃO - Classe: AC - APELAÇÃO CIVEL 436789. UF:SP - Data da decisão: 12/06/2001.Documento: TRF300055973. Relator: juiz Olveira Lima. PREVIDENCIÁRIO. ASSITÊNCIA SOCIAL. INCAPAZ. INCAPACIDADE COMPROVADA. HIPOSSUFICIÊNCIA COMPROVADA. HONORÁRIOS ADVOCATÍCIOS E PERICIAIS. JUROS DE MORA. CORREÇÃO MONETÁRIA. DIES A QUO DO BENEFÍCIO. 1) Remessa oficial tida por interposta, nos termos do artigo 475, "caput" e inciso II, CPC. Lei no 9.469/97. 2) O pedido na inicial é do amparo previdenciário previsto no art. 203 da Constituição Federal, não havendo que se falar de impossibilidade jurídica do pedido pela extinção da renda mensal vitalícia. 3) A assistência social está garantida aos portadores de deficiência física e ao idoso (artigo 203, inciso V, da Constituição Federal - Lei no8.742/93 - Decreto no 1.744/95). 4) Comprovada a incapacidade total e permanente do autor, bem como a falta de condições para prover seu próprio sustento ou tê-lo provido por outrem, de quem dependa obrigatoriamente, faz ele jus ao benefício da assistência social. [...].

E mais:

TRIBUNAL REGIONAL FEDERAL - 3o REGIÃO - Classe: AC - APELAÇÃO CIVEL 843337.Processo: UF: SP.Data da decisão: 04/08/2003. Documento: TRF300073377 . Relator: Juíza Leide Pólo. PREVIDENCIÁRIO - ASSISTÊNCIA SOCIAL PORTADOR DE DEFICIÊNCIA - PROVA PERICIAL E TESTEMUNHAL - RECURSO DE APELAÇÃO E REMESSA OFICIAL PARCIALMENTE PROVIDOS. 1. O benefício assistencial exige o preenchimento de dois requisitos para a sua concessão, quais sejam: primeiro, ser o requerente portador de deficiência que o torna incapaz para a vida independe e para o trabalho e, segundo, não possuir meios de prover à própria manutenção ou de tê-la provida por sua família. 2. Nestes autos, o laudo pericial atesta a incapacidade total e permanente da Autora para o trabalho. E a prova oral produzida comprova que a condição financeira da Autora e de sua família é incapaz de alcançar o mínimo necessário para sobrevivência. 3. Presentes os requisitos exigidos pelo art. 203, inciso V, da Constituição Federal através das provas trazidas aos autos, deve-se conceder o amparo social. 4. Redução da verba honorária advocatícia (artigo 20, §§ 3 e e 4ㅇ do Código de Processo Civil).

Finalmente, para se fazer justiça às pessoas que possuem certas limitações, seja por incapacidade física ou mental ou idade avançada, deve-se colocar plenamente em prática os 
dispositivos constitucionais, para somente assim, satisfazer os anseios dos cidadãos brasileiros e respeitar seus direitos fundamentais - direito a uma vida digna.

Das condições pessoais do requerente idoso e do direito ao beneficio de prestacao continuada assistencial

A incapacidade para fins de concessão de benefício assistencial não precisa ser absoluta, basta que impossibilite a vida laboral, afinal, o deficiente físico ou o idoso não precisam depender dos outros para todos os atos de suas vidas.

Logo, não restam dúvidas de que, em não sendo o deficiente ou idoso apto para o trabalho, certamente não poderá manter sua própria subsistência sem depender economicamente de outrem. Necessário ressaltar que um idoso com 65 anos não é mais aceito no mercado de trabalho.

Portanto, para fins de concessão de amparo social ao idoso, basta a prova da incapacidade laboral, sendo desnecessária a cumulatividade desta com a incapacidade para todo os atos da vida cotidiana, tais como higiene, alimentação e aptidão para vestir-se sozinho.

Insta mencionar que, constantemente, em sede administrativa, os laudos médicos confeccionados pelos peritos do Requerido têm sido alvo de enormes críticas, tendo em vista que exigem incapacidade não apenas para o trabalho, mas também para os atos da vida cotidiana, gerando verdadeira lesão a direitos.

A Lei 8.742/93, Lei Orgânica da Assistência Social (LOAS), que regulamenta o artigo 203, V , da Carta Magna, definiu apenas que a renda familiar inferior a $1 \frac{1}{4}$ do salário mínimo é, objetivamente considerada insuficiente para que um idoso consiga sobreviver.

Ademais, ela não afasta outros meios de prova da condição de miserabilidade do necessitado e de sua família.

A esse respeito, vale destacar que a renda per capita familiar não é o único meio de prova de miserabilidade, ou seja, há outros meios de prova dessa condição e, nesse sentido, decidiu a Turma Nacional de Uniformização da Jurisprudência dos Juizados Especiais Federais, processo 2002.70.0900.7310-0, em sessão de julgamento realizada em Florianópolis/SC, que ocorreu no encontro nacional dos Juizes Federais.

O relator do processo foi o Juiz Federal Leomar Amorim, que assim sentenciou: 
A renda familiar inferior a $1 / 4$ do salário mínimo deve ser considerada como um limite mínimo, objetivamente considerado insuficiente à subsistência do portador de deficiência e do idoso, o que não impede que o julgador faça uso de outros fatores que tenham o condão de comprovar a condição de miserabilidade da família do autor. Acórdão da 5ạ Turma do STJ, de 21/10/2002, no Recurso Especial 435.871/SP.

E ainda, as jurisprudências dos Tribunais são no sentido de que a comprovação de renda familiar per capita, superior a $1 / 4$ do salário mínimo, não exclui a condição de miserabilidade.

Portanto, havendo prova da condição de miserabilidade do idoso e de sua família, mesmo que a renda per capita seja superior ao limite de 1/4 do salário mínimo e idade de 65 (sessenta e cinco) anos ou mais.

\section{A polêmica sobre a idade para concessão do beneficio assistencial}

Sob a ótica das considerações sobre a Lei Orgânica da Assistência Social, pode-se afirmar que seu advento foi de suma importância para o ordenamento jurídico brasileiro, sendo visto com um instrumento útil de ressocialização.

Desta forma, nota-se que, na atualidade, a sociedade é carente de recursos e de informações acerca de seus direitos, principalmente a camada hipossuficiente da população, pois mesmo com a existência do benefício de prestação continuada previsto na Lei da Assistência Social, há muito que se melhorar em termos de assistência e desburocratização.

Dentre as propostas ofertadas à melhoria da concessão do Benefício de Prestação Continuada contido na Lei Assistencial, a que gera mais polêmica refere-se à idade, hoje sendo de 65 (sessenta e cinco) anos para que o assistido possa receber tal benefício.

O entrave inicia-se com a edição da Lei no. 10.741/03 que regula o Estatuto do Idoso, pois separou tal conceito em duas partes distintas: o idoso propriamente dito, ou seja, pessoa com idade igual ou superior a 60 (sessenta) anos, nos termos do artigo 10, bem como o idoso, para fins de concessão do benefício de prestação continuada, aquele com 65 (sessenta e cinco) anos ou mais, nos termos do artigo 34.

Contudo, acredita-se que neste momento o próprio legislador poderia ter unificado tanto o conceito de pessoa idosa como a concessão do benefício assistencial. 
É de se observar se tal omissão, proposital ou não, resultou ou não em prejuízos aos idosos de hoje, uma vez que ao ingressar com o requerimento administrativo ou judicial caberá ao órgão responsável sua apreciação e resolução do caso em concreto, aplicando, assim, o princípio da dignidade da pessoa humana.

Fala-se muito em expectativa de vida hodiernamente, a qual sempre vem aumentando a cada dia, o que pode justificar a mantença da idade de 65 anos para a concessão do benefício assistencial. Mas, raciocinando pelo lado do princípio da dignidade humana, e por que não dignidade necessária, sendo todos humanos e, sendo a dignidade o sustento da Constituição Federal, todo independente da idade, fariam jus ao Benefício de Prestação Continuada Assistencial, desde que comprovados outros requisitos mais importantes, como a hipossuficiência, a dependência econômica, renda per capita.

Enfim, no benefício assistencial não incide o fator previdenciário como nos demais benefícios previdenciários, mas sim requisitos de hipossuficiência relacionados aos benefícios assistenciais.

Tudo isso se explica pelo princípio da dignidade humana, sendo que este é o fundamento da Constituição Federal, pelo qual todos os cidadãos são dignos de uma vida saudável. Por isso, o termo usado acima, dignidade necessária, pois se acredita que se trata de um direito fundamental e que não deveria estar em capítulo separado lá no artigo 203 da Constituição Federal de 1988, mas sim no artigo 5으, no qual se encontram as garantias fundamentais.

Entretanto, na falta cometida pelo legislativo, ainda se tem em dois caminhos conceituais distintos: o idoso e o idoso para fins de concessão do benefício de prestação continuada assistencial.

\section{Ativismo judicial}

Necessário, a priori, definir o chamado ativismo judicial. Esse instituto surgiu com o fim da segunda guerra e a hegemonia da Constituição, ressaltando o advento do póspositivismo e a ascensão dos direitos fundamentais, bem como dos princípios que sustentam a Carta Magna e da decadência do constitucionalismo liberal, relacionando-se com a participação efetiva dos magistrados no controle da constitucionalidade. 
A doutrina conceitua o ativismo judicial como "uma postura a ser adotada pelo magistrado que o leve ao reconhecimento da sua atividade como elemento fundamental para o eficaz e efetivo exercício da atividade jurisdicional" (DELGADO, 2008, p. 139). Nesta linha, vê-se claramente que o ativismo judicial é uma postura que, ao ser adotado pelos exercentes da função jurisdicional, faz com que recusem outra postura.

Dworkin (2010) explica essa postura da seguinte forma:

[...] o programa da moderação judicial afirma que os tribunais deveriam permitir a manutenção das decisões dos outros setores do governo, mesmo quando elas ofendam a própria percepção que os juízes têm dos princípios exigidos pelas doutrinas constitucionais amplas, excetuando-se, contudo, os casos nos quais essas decisões sejam tão ofensivas à moralidade política a ponto de violar as estipulações de qualquer interpretação plausível, ou, talvez, nos casos em que uma decisão contrária for exigida por um precedente inequíoco.

Assim, sendo um movimento contrário a tal postura, o ativismo judicial exige que os juízes sejam atuantes no sentido não apenas de fazer cumprir a lei em seu significado exclusivamente formal, mas exige audácia na interpretação de princípios constitucionais abstratos tais como a dignidade da pessoa humana, igualdade, liberdade, reivindicando, então, para si a competência institucional e a capacidade intelectual para fixar tais conceitos abstratos, atribuindo significado preciso aos mesmos, concretizando-os, bem como julgar os atos dos outros poderes que interpretam estes mesmos princípios.

Enfim, o ativismo judicial é entendido pela maioria como a ampliação do poder dos tribunais no controle dos demais poderes, por meio do viés constitucional. Em março de 2006 o Ministro Celso de Mello em entrevista ao site Consultor Jurídico indicou algumas das vantagens do ativismo jurídico concretamente no Brasil e da sua importância para a democracia, entre elas:

\begin{abstract}
- atuação do judiciário como "co-partícipe do processo de modernização do Estado brasileiro;

- suprir as lacunas da legislação para que prevaleça o espírito da Carta de 1988, uma vez que a formulação legislativa no Brasil, segundo ele, lamentavelmente, nem sempre se reveste da necessária qualidade jurídica, o que é demonstrado não só pelo elevado número de ações diretas promovidas perante o Supremo Tribunal Federal, mas, sobretudo, pelas inúmeras decisões declaratórias de inconstitucionalidade de leis editadas pela União Federal e pelos Estados-membros sendo esse déficit de qualidade jurídica preocupante porque afeta a harmonia da Federação, rompe o necessário equilíbrio e compromete, muitas vezes, direitos e garantias fundamentais dos cidadãos da República." ${ }^{2}$
\end{abstract}

\footnotetext{
${ }^{2}$ Disponível em: http://www.conjur.com.br/2006-mar-15/juizes_papel_ativo_interpretacao_lei.
} 
A verdade é que hoje o poder judiciário, segundo seus próprios membros e de muitos doutrinadores, exerce um poder moderador, visando equilibrar a tripartição dos poderes. É com o controle de constitucionalidade abstrato que o Poder Judiciário tem sistematicamente decidido sobre questões de diversas naturezas.

Insta salientar que o surgimento do ativismo judicial está relacionado com a decadência do constitucionalismo liberal e da política neoliberal, voltado a uma visão mais humanista e social, preservando princípios basilares de um Estado que são representados por sua Constituição e, principalmente, realçando axiologicamente os direitos fundamentais, mais especificamente aqueles que dizem respeito à dignidade da pessoa humana.

Neste ponto, a deficiência legislativa ou a má utilização de instrumentos políticos que possam abalar tais direitos e princípios são objetos dos tribunais que com o ativismo judicial protegem valores tão importantes para a sociedade.

Com o advento do pós-positivismo também não se pode querer que o Poder Judiciário desconsidere as repercussões sociais e políticas de suas decisões.

O déficit democrático com certeza é um dos grandes obstáculos ao ativismo judicial, afinal, por melhores que sejam as cabeças presentes no Supremo Tribunal Federal, os temas que hoje por eles são decididos estão afastados do povo, já que nenhum deles foi eleito democraticamente e não representam a vontade de uma maioria.

Indaga-se ao grande personagem deste ativismo judicial, o Supremo Tribunal Federal, se em razão deste déficit pode decidir, legislar, ou concentrar tais poderes em detrimento dos outros poderes ou até dos magistrados monocráticos ou tribunais estaduais que estão bem mais próximos dos jurisdicionados.

Nota-se que o berço do ativismo judicial é o maior exemplo de que tal fenômeno pode vir a ser de grande utilidade para a democracia, bem como ser capaz de trazer enormes prejuízos.

O fato é que o ativismo judicial pode assumir um foco diverso dos anseios populares, ou até contrários aos interesses do país. Hodiernamente, está-se diante da Corte Suprema mais ativista do mundo, decidindo, desde a antecipação terapêutica do parto (ou aborto, a depender do ponto de vista) em feto anencéfalo e demarcação efetuada pelo Ministério da Justiça da reserva indígena "Raposa do Sol", até o nepotismo, sem que se saiba 
exatamente se aqueles a quem o povo escolheu fariam leis no exato direcionamento das decisões do STF.

O magistrado não pode ser mero aplicador de leis, e que os princípios, ainda que não escritos, são maiores que muitas leis positivadas, pois neles se baseiam a Constituição.

A propositura de uma investigação nas diretrizes de funcionamento do sistema jurídico, não só no brasileiro, mas em toda América Latina, revelaria o quão é exigido do juiz uma altíssima produtividade de decisões no menor espaço-tempo processual possível, chegando-se a torná-la critério constitucional objetivo de promoção por merecimento. Contudo, mesmo que possível a um juiz com formação extremamente plural antever os impactos de suas decisões, há a necessidade de se ofertar ao mesmo uma infra-estrutura idônea para tal.

A solução encontra-se no próprio processo: a decisão do juiz deve ser tal que resulte da co-participação de todos os sujeitos processuais no processo. Assim, se, por exemplo, em um caso sobre saúde, se argumenta que a decisão vai implicar em danos ao erário (e isso implicará na falta de recursos para outros usuários do sistema), tal não pode ser pressuposto, quer pelo juiz, quer pela Administração Pública, mas amplamente provado e debatido nos autos, de forma que o Poder Público, de forma transparente e clara, demonstre suas razões, em contraditório com o autor.

Logo, o que se tem, em boa parte das discussões e julgados, entretanto, são tentativas de fazer com que o juiz avalie, não o caso que tem diante de si, mas eventuais (e supostas) repercussões sociais, econômicas, políticas e jurídicas de sua decisão. O problema dessa racionalidade está em que os direitos fundamentais não podem ser tratados em uma relação pragmática de custo-benefício.

O Ativismo judicial e a concessão do beneficio de prestação continuada assistencial aos idosos 
Como foi demonstrado, o que ainda está em vigência é o critério etário de 65 anos para concessão do benefício assistencial aos idosos, bem como é o que a maioria dos juízes têm decidido.

Por outro lado, têm-se estudiosos aplicadores do direito que exercem função atípica, revelando o lado social do gênero Seguridade Social: a assistência social. Logo, esse caráter social, entendido pela minoria, é levado em consideração quando o assistido preenche os requisitos mínimos, como hipossuficência, dependência econômica, renda per capita de até $1 / 4$ do salário mínimo, momento em que pouco importa a idade, se 60 ou 65 anos, o benefício de prestação continuada é concedido.

Trata-se, portanto, de um ativismo judicial revelador, no qual parte-se de uma norma já existente (Estatuto do Idoso), correlacionado ao princípio da dignidade humana e, assim, o magistrado entende necessária a concessão naquele dado momento, pois, $a$ posteriori, poderá ser tarde.

São poucos os julgados, mas possíveis de serem encontrados, como segue:

Processo: 2008.03.99.010394-5 UF:SP

Classe: AC - APELAÇÃO CÍVEL - 1286603

№ DOCUMENTO: 1/5955 TRF 300293019

RELATOR: DESEMBARGADORA FEDERAL MARIANINA GALANTE

ÓRGÃO JULGADOR: OITAVA TURMA

DATA DO JULGAMENTO: 31/05/2010

DJF3 CJ1 DATA:27/07/2010 PÁGINA: 1077

EMENTA: PREVIDENCIÁRIO. AGRAVO LEGAL. BENEFÍCIO ASSISTENCIAL. PREENCHIDOS OS REQUISITOS LEGAIS. DECISÃO FUNDAMENTADA. TERMO INICIAL MANTIDO NA DATA DA CITAÇÃO.

I - É pacífico o entendimento nesta E. Corte, segundo o qual não cabe alterar decisões proferidas pelo relator, desde que bem fundamentadas e quando não se verificar qualquer ilegalidade ou abuso de poder que possa gerar dano irreparável ou de difícil reparação.

II - Preenchidos os requisitos necessários para concessão do benefício assistencial , à luz do inciso V, do art. 203 da Constituição Federal, c.c. o art. 20 da Lei no. $8.742 / 93$, quais sejam: 1 ) ser pessoa portadora de deficiência que a incapacite para o trabalho, ou idoso com 65 (sessenta e cinco) anos ou mais, conforme o artigo 34, do Estatuto do Idoso (Lei no 10.471/2003) e 2) não possuir meios de subsistência próprios ou de seus familiares, cuja renda mensal per capita deve ser inferior a $1 / 4$ do salário mínimo.

III - Demanda proposta em 31.03.2004, quando a autora possuía 60 anos (nascida: 09.10.1944).

IV - Estudo social (fls. 26/27), datado de 11.11.2004, informa que a autora reside em casa própria, com o marido, mesmo estando separada de fato (núcleo familiar de 2 pessoas). A renda de 0,53 salários-mínimos, advém da locação do imóvel nos fundos da residência (0,15 salários-mínimos) e dos "bicos" de jardineiro realizados pelo cônjuge (0,38 salários-mínimos). O casal é doente faz uso de diversos medicamentos. A requerente deficiente física (seqüela de pólio, com atrofia muscular no membro inferior direito, déficit motor e uso de prótese, em razão de 
fratura óssea), faz uso de cadeira de rodas e o marido possui problemas renais. Recebem ajuda dos vizinhos e dos filhos, que tem suas próprias famílias constituídas.

V - Demonstrada a hipossuficiencia, considerando que o núcleo familiar é composto por 2 pessoas, doentes, que fazem uso de medicamento, com renda de 0,53 salários-mínimos.

VI - A decisão mantida, para que seja concedido o benefício ao requerente, que comprovou a situação de miserabilidade, à luz da decisão do E. STF (ADI 1232/DF Julgado - 27/08/98 - Rel. Min. Ilmar Galvão), em conjunto com os demais dispositivos da Constituição Federal de 1988.

VII - Termo inicial mantido na data da citação (12.05.2004), momento que a Autarquia tomou ciência da pretensão da autora, conforme entendimento firmado por esta E. Turma.

VIII - O benefício requerido nesta demanda é diverso dos previdenciários de natureza contributiva, tais como auxílio-doença e aposentadoria por invalidez, em que a jurisprudência unificou entendimento de que o termo inicial deve ser fixado na data do laudo que constate a enfermidade. Cuida-se de prestação de natureza assistencia, em que o estudo social e laudo atestam situação já existente de deficiência e penúria, que deve ser amparada.

IX - Agravo não provido.

ACÓRDÃO: Vistos e relatados estes autos em que são partes as acima indicadas, decide a Egrégia Oitava Turma do Tribunal Regional Federal da 3a Região, por unanimidade, negar provimento ao agravo legal, nos termos do relatório e voto que ficam fazendo parte integrante do presente julgado.

No caso apresentado, o magistrado concedeu o benefício assistencial a um idoso com menos de 65 anos, pois não levou em conta apenas sua idade, mas o conjunto de fatores que o ensejaram ao requerimento de tal benefício.

Muito bem colocado, o magistrado, em sua sensibilidade, observou a renda per capita, a miserabilidade, o clã familiar e, mesmo o requerente possuindo menos de 65 anos, concedeu o benefício de prestação continuada assistencial ao idoso, levando em consideração o Estatuto do Idoso, posterior à lei de assistência social.

Agravo foi proposto em 22/10/2008, data em que o Autor contava com 64 (sessenta e quatro) anos, ou seja, idade aquém da exigida em lei.

Assim, presencia-se um caso de ativismo judicial revelador, pautado numa lei posterior àquela que regula determinado assunto, dando prioridade, uma vez que o requerente preencheu os demais requisitos.

\section{Conclusão}


A Lei 8.742/93 que regula a Assistência Social estabelece a idade mínima de 65 anos para a concessão do benefício de prestação continuada para o idoso, quando o Estatuto do Idoso (Lei 10.741/2003), posteriormente, dispõe que idosa é toda pessoa de idade igual ou acima de 60 anos, porém, no que tange a benefícios da Seguridade Social, a idade prevaleceu ainda 65 anos.

O Estatuto do Idoso poderia ter regulado uma única idade para a concessão do Benefício de Prestação Continuada Assistencial ao idoso, mas ao contrário, manteve a idade estabelecida pela Seguridade Social.

Entende-se que tal restrição não pode perdurar por muito mais tempo, uma vez que a população brasileira que já é carente e necessitada, e que já tem ou está a ponto de completar 60 (sessenta) anos, deverá esperar até 05 (cinco) anos para a concessão de um benefício que há muito já poderia ser-lhe concedido.

Por esta razão, existe uma real necessidade de alteração do texto do artigo 34 da Lei $n$ ‥ 10.741/03, o qual restringe o benefício de prestação continuada aos maiores de 65 (sessenta e cinco) anos, adequando-a, dessa forma, aos novos e mais abrangentes diplomas legais existentes. Diz-se ponto crítico, pois se tem uma lei que classifica a pessoa como idosa aos 60 anos, sendo que esta mesma lei trata em um de seus capítulos sobre a assistência social, no qual mantém a idade de 65 anos para a concessão do amparo social.

Há de ressaltar que a natureza e a essência do benefício e/ou assistência social é a de beneficiar a quem dela necessitar, independentemente de contribuição à seguridade social, garantindo o valor de um salário mínimo de benefício mensal à pessoa portadora de deficiência e ao idoso que comprove não possuir meios de prover à própria manutenção ou de tê-la provida por sua família, conforme dispõe a Lei Maior (art. 203)

Assim constatadas a idade avançada e a carência de condição de sobrevivência digna, impõe-se à concessão do benefício de natureza assistencial.

Portanto, as restrições contidas no artigo 20, § 3으 - Lei ํo. 8.742/1993, e a idade imposta pelo artigo 34 do Estatuto do Idoso, são inconstitucionais, na medida em que limitam o comando constitucional, deferindo o benefício apenas aos idosos ou que obtiverem renda familiar per capita inferior a 1/4 do salário mínimo. 
A propósito, a Lei 8.742/93, que regulamenta o artigo 203, V, da Carta Magna, quis apenas definir que a renda familiar inferior a $1 / 4$ do salário mínimo é, objetivamente considerada insuficiente para que um idoso (ou deficiente) consiga sobreviver.

Ademais, ela não afasta outros meios de prova da condição de miserabilidade do necessitado e de sua família. Momento em que se faz necessária a atuação mais social do magistrado, utilizando-se do ativismo judicial revelador para efetivar o princípio da dignidade da pessoa humana.

Aliás, o Direito está cada vez mais principiológico do que normativo. Há uma visível transição do Direito normativista para o Direito axiológico. Então, a importância dos princípios como instrumento para superar a rigidez normativa e alcançar a razão e a justiça. A mudança de paradigma teve muita contribuição de Ronald Dworkin e Robert Alexy.

A ordem jurídica passou a ser encarada como um sistema aberto de princípios e regras, suscetíveis a valores jurídicos positivados, na qual a ideia de justiça desempenha papel fundamental, inclusive no processo ideal.

Conclui-se que o ativismo judicial tem papel importante na atuação do magistrado, efetivando a tutela jurisdicional, a qual tem como pano de fundo o princípio da dignidade humana em prol daqueles que são menos favorecidos, proporcionando a eles uma vida mais digna.

\section{Referências}

ALEXY, Robert. Teoria de los derechos fundamentales. Madrid: Centro de Estudios Constitucionales, 1993.

ARISTÓTELES. Ética a Nicômaco. Tradução de Leonel Vallandro e Gerd Bornheim da versão inglesa de W. A. Pickard. São Paulo: Abril Cultural, 1973.

BALERA, Wagner. A Seguridade Social na Constituição de 1988. São Paulo: Revista dos Tribunais, 1989.

BITTAR, Eduardo C. B. A justiça em Aristóteles. Rio de Janeiro: Forense Universitária, 1999.

CANOTILHO, J. J Gomes. Direito Constitucional e Teoria da Constituição. Coimbra: Almedina. 1988.

CAPPELLETTI, Mauro; GARTH, Bryant. Acesso à Justiça. Tradução de Ellen GracieNorthfleet. Porto Alegre: Fabris, 1988. 
CHUERI, Vera Karam de. Filosofia do Direito e modernidade. Dworkin e a possibilidade de um discurso instituinte de direitos. Curitiba: JM editora, 1995.

DALLARI, Dalmo de Abreu. Elementos de Teoria do Estado. 11 ed. São Paulo: Saraiva, 2010.

DELGADO, José Augusto. Ativismo Judicial: o papel político do poder judiciário na sociedade contemporânea. In: PROCESSO Civil Novas Tendências: homenagem ao Professor Humberto Theodoro Jr. Belo Horizonte, Del Rey, 2008.

DWORKIN, Ronald. Levando os direitos a sério. Trad. Nelson Boeira. São Paulo: Martins Fontes, 2002.

DWORKIN, Ronald. Levando os direitos a sério. Tradução de Nelson Boeira. São Paulo: Martins Fontes, 2010.

FREITAS, Juarez. A interpretação sistemática do direito. Malheiros: São Paulo, 2002.

HART, Herbert L. A. O conceito de Direito. Lisboa: Calouste Gulbelkian, 1986.

KANT, I. Fundamentação da Metafísica dos Costumes. Tradução Paulo Quintela. Textos Filosóficos. Lisboa: Edições 70, 1997.

MARTINS, Flademir Jerônimo Belinati. Dignidade da Pessoa Humana: princípio Constitucional Fundamental. Curitiba: Juruá Editora, 2003.

MARTINEZ, Wladimir Novaes. A Seguridade Social na Constituição. São Paulo: LTR, 1922.

MELLO, Celso Antônio Bandeira. Conteúdo Jurídico do Principio da Igualdade. São Paulo: Malheiros, 1999.

NALINI, José Renato. O Juiz e o Acesso à Justiça. São Paulo: Editora Revista dos Tribunais, 1994.

POZZOLI, Lafayette. Maritain e o Direito. Edições Loyola. São Paulo, 2001. (Coleção Instituto Jacques Maritain do Brasil).

REALE, Miguel. Filosofia do direito. São Paulo: Saraiva. 2002.

RIZZATTO NUNES, Luiz Antonio. O princípio constitucional da dignidade da pessoa humana: doutrina e jurisprudência. São Paulo: Saraiva, 2002.

SALGADO, Joaquim Carlos. A idéia de justiça em Kant - seu fundamento na liberdade e na igualdade. Belo Horizonte: UFMG, 1986.

SARLET, Ingo Wolfang. Dignidade da pessoa humana e direitos fundamentais na Constituição Federal de 1988. Porto Alegre: Livraria do Advogado, 2002.

SILVA, De Plácido e. Vocabulário Jurídico. Rio de Janeiro: Forense. 1989. v.3. 
STERN, Klaus. O juiz e a aplicação do direito. Direito constitucional: estudos em homenagem a Paulo Bonavides. São Paulo: Malheiros Editores, 2003.

Artigo recebido em:

06 de abril de 2011.

Artigo aprovado em:

01 de maio de 2011. 